\title{
The application and practice of the coach technique in university innovation and entrepreneurship education
}

\author{
Qiang $\mathrm{Yu}^{1, \mathrm{a}}$, Lili Huang ${ }^{1, \mathrm{~b}}$, Lin Guo ${ }^{1, \mathrm{c}}$, Pengbo Shang ${ }^{2, \mathrm{~d}}$ \\ ${ }^{1}$ Harbin University Harbin China \\ ${ }^{2}$ Tsting University Beijing China \\ ayuqiang0708@163.com, bhll305@sina.com, cgl208@163.com, dpablo_shang@aotuke.com
}

Keywords: Application and practice, Coach technique, Innovation and entrepreneurship.

\begin{abstract}
For many years, innovation and entrepreneurship education work in China's college students training education has been unclear. Some education managers have misconceptions about innovation and entrepreneurship education works. Therefore, the education work for college students lacks the uniform standard of education goal,the more important is the lack of scientific and effective practice approach of innovation and entrepreneurship education.In this paper, the coach technique is used as a scientific and effective method of practical teaching,to discusses the methods and techniques of the coach technique in innovation and entrepreneurship education, and summarizes the advantages and characteristics of the coach technique in the practice teaching of innovation education in college students.
\end{abstract}

\section{教练技术在高校创新创业教育中的应用与实践}

\author{
于强 $1, \mathrm{a}$, 黄丽丽 $1, \mathrm{~b}$, 郭林 ${ }^{1, \mathrm{c}}$, 尚鹏博 $2, \mathrm{~d}$ \\ 1哈尔滨学院, 哈尔滨, 黑龙江, 中国 \\ 2清华大学, 北京, 中国
}

ayuqiang0708@163.com, bhll305@163.com, ’gl208@163.com, dpablo_shang@aotuke.com

关键词：教练技术; 创新创业教育; 应用与实践

中文摘要. 多年来, 创新创业教育工作在中国的大学生人才培养教育中的定位一直不够明确, 部分教育管理者对创业教育工作的认识和理解存在误区, 因此, 导致对大学生的双创教育工 作缺少教育目标的统一标准, 更重要的是缺少科学有效的双创教育指导实践的方法。本文将 教练技术做为一种科学高效的实践教学方法, 探讨了教练技术在指导大学生双创教育工作中 应用实践的方法和技巧，从而总结出教练技术在大学生双创教育实践中的优势和特点。

\section{1. 创业教育发展现状及不足}

2012年8月1日, 由教育部高教司下发的《普通本科学校创业教育教学基本要求 (试行)》 的通知 (教高厅 [2012]4号) 文件, 开启了我国大学生创业教育的整体规划和建设实施的战略 步伐，在教育部和地方政府的共同推动作用下，在高等院校和部分教师的积极参与努力下， 我国的大学生创业教育掀起了一轮理论研究和实践探索的热潮。尤其在大学生创业教育的课 程体系建设和实践指导应用上几年来积累了一些经验, 取得了一定成绩。大学生的创业教育 越来越受到教育主管部门的重视以及社会企业的广泛关注。然而, 大学生的创业教育在人才 
培养方案中的课程定位, 以及在与不同层次和不同专业的大学生人才培养目标对接上还没有 形成广泛的共识和标准。在对创业教育本身如何科学评价, 课程及教材选择、教学原则和教 学方法等尚处于前期摸索和验证阶段, 不同高校在对待创业教育的教学组织和管理上存在较 大差异化、不同地区的政府及教育主管部门的认识和投入参差不齐，导致目前的创业教育存 在多元化的理论研究和教学理念, 在教学方法和指导实践应用中有的还停留在SYB和KAB等 传统创业教育课程的理念和教学内容上并无创新和实践应用上的突破。事实证明, 创业教育 以及创业教育的课程建设必须从创业实战的应用效果入手。

\section{2. 教练技术的由来及特点}

\section{1 创业教练技术的由来}

创业教练技术源自于管理教练技术。现代企业已经步入到了信息化时代背景下的经营和 管理, 企业所面临的商业环境已经由传统的工业经济向知识经济转化, 在欧美等发达国家的 企业管理创新摸索中逐渐总结形成了一套全新的企业管理模式，也被称为 “知识经济企业管 理新技术”。新的管理模式让企业的管理者向教练身份转变, 在这种创新型的管理模式下, 企业的管理者开始尝试以目标为核心, 以成果为导向, 通过积极的聆听和有效的对话, 激发 员工的智慧, 从而快速地将目标转化为成果, 形成企业竞争的核心动力。这套创新的管理模 式造就了一种全新的企业管理技术就是管理教练技术。自管理教练技术引入到中国以来的 10 余时间里, 随着中国经济社会的快速发展, 更多的中国企业管理者开始学习和接受管理教练 技术在企业中的应用实践和效果。经过多年来管理教练在国内外企业的成功实践和应用, 管 理教练技术已经得到了企业用户的认可和信赖, 同时也经受住了市场环境变化所带来的挑战。

管理教练技术在企业管理应用中的成果就是形成了企业教练这一创新的管理思维和理 念, 在当今的企业市场竞争中成为了管理决策者一项十分有效的管理工具, 从2015年以来, 管理教练技术开始被引入到高校的大学生创业教育以及大学生创业项目的实践指导工作中取 得了极大影响的收获了具大的成功, 并由此形成并开启了创业教练技术在高校大学生创业教 育中的应用实践。实践证明, 创业教练技术对于以往高校中从事创就业教育和辅导的一线教 师们来说, 这种简单科学高效的教学思维方法正成为他们指导大学生摆脱创业困惑突破创业 瓶颈的有利工具。

\section{2 教练技术的特点}

应用于企业管理中的管理教练其定义为：通过有效对话，引发员工的智慧，激发员工醒 觉性与尽责感, 从而快速提升员工绩效的管理技术。教练技术的特点是以人为本, 相信被教 练对象具有解决问题的智慧。教练技术具有严谨的架构体系, 在架构体系的支撑下从目标到 成果形成了完整的价值管理模式, 通过有效对话能够让被教练者主动思考, 理清现状, 确定 方向, 明确目标。在高校从事创就业的教师们, 长期以来都存在一个共同的困惑就是自身缺 少创业的经历和经验, 导致老师们在给学生做创业教育或项目指导时经常陷入一种不自信的 塩尬境地, 更有很多老师会不由自主地陷入经验指导的陷阱和误区, 创业教练技术的出现正 好帮助这些从事创业教育的一线教师们摆脱了这种塩尬和误区, 越来越多的创业指导教师通 过学习和运用教练技术实现了引导创业学生智慧和思维去解决学生自身创业实际问题的高效 辅导, 让更多的创业指导教师能够更有效的与创业学生进行交流和沟通, 指导的效果也越来 越好。

\section{3. 教练技术在创业教育指导实践中的应用}

创业是最高层次的就业, 随着中国制造向中国创造的转变, 大学生的双创教育正在以全 新的教育理念和培养模式深度融合于人才培养的每一个阶段。然而, 由于我国创业教育起步 
晚认识落后, 虽然, 有些院校十分重视创业教育工作的开展, 成立了相应的创业学院或大学 生创业指导中心等专职于双创教育工作的教学辅助部门, 但是师资队伍的培养还需要一个过 程, 长期以来高校中严重缺少专业性的双创教育教资团队建设, 导致多数高校中从事创就业 教育指导工作的一线工作者仍然由辅导员或没有创业经历的从事招生就业行政工作的教师兼 任, 当前的这一格局还很难在短时间内得到较大改善。因此, 如何为这些本就日常工作十分 琐碎和繁忙的辅导员老师们提供一项好学好用而又有效的创业指导技术就显得尤为迫切和必 要。教练技术正是这样一种上手快, 容易掌握并且能够最大限度激发学生创业智慧的有效的 创业实践指导技术。教练技术就是要让我们的老师向创业教练的身份转变, 教练技术的有效 性在指导学生创业教育工作中的应用过程中主要表现在以下几方面。

\section{1 有效对话}

创业教练的对话技术能够让我们的教练老师在与创业学生交谈中做到发现性、扩展性和 动力性的特点。当一个怀揣创业梦想或创业灵感的学生找到老师去寻求帮助和指导时, 由于 我们的学生经验或能力不足的原因, 经常会陷入到自己的不切实际的愿景目标中难以自拔, 没有经过教练技术学习的指导老师往往会在这种与学生的沟通交谈中随着学生的夸夸其谈而 迷失创业指导的方向的重点, 最后我们给学生的任何建议或帮助对于学生来说都可能是错误 的或不是学生真正想要的。而那些接受过教练技术学习和训练的教练老师, 他们就可以帮助 学生穿透自己的思维演绎看清其创业项目或创业目标的客观事实。只有让学生的愿景目标精 准转化成为可具执行力的行动目标才能让我们的创业指导真正收到效果, 让学生得到帮助。 导致两种截然不同的交谈对话结果的原因就是教练技术的有效对话方法和技巧。对于创业指 导教师来说, 要想实现与学生的有效对话, 需要学习两方面的技术, 一方面是如何聆听, 另 一方面是如何发问。

\section{1 .1 有效聆听}

有效对话的前提是学会聆听。创业教练通过聆听技术能够穿透学生或慷慨激昂或沉思忧 郁的表达陈述中看到事实真相。只有当创业教练掌握了聆听技术才能激发学生有动力的与你 交谈, 当学生能够敞开心扉跟我们畅所欲言时, 他会自觉地去思考, 经过思考学生的创业智 慧才能完全显现出来。对于教练技术在创业指导中的实践来说, 聆听不仅是在用耳朵听, 更 重要的是对被教练对象的重视、理解和尊重, 教练要做到忍耐, 避免打断对方思路, 要留给 被教练对象一个完整清晰的表达陈述的机会, 这样能够促进学生们的思维自醒, 帮助学生创 造性的开启思考和解决问题的智慧之门。我们把这种聆听技术称为有效聆听。

\section{1 .2 如何发问}

在有效对话中，创业教练如何发问，问学生什么问题一直是高校创业导师们的最大困惑， 这跟我们学校从事创业指导工作的老师们缺少创业经历和经验, 缺乏有效创业指导方法有直 接关系。彼得 - 德鲁克曾经说过 “最严重的错误, 不是给出错误的答案, 而是针对错误的问 题作答。我们需要的不是正确的答案, 而是正确的问题。” 其实, 创业教练的发问能力是一 个操作性很强的技巧, 但是发问的核心重点就是要针对关键词发问。这跟传统创业辅导最大 的不同就体现在发问是否能够切入重点和主题, 没有接受过创业教练技术培训的老师可能像 学生一样很善谈, 但是天马行空的跟学生说了很多却都不是学生关注的重点, 而且经常会陷 入经验辅导的误区, 通过跟学生例举大量创业成功人士的案例来激励学生, 但是往往效果并 不是很好, 甚至于误导学生在错误的方向上不断试错不停地做着无用功。导致这样结果的原 因就在于经验辅导在应用于学生创业辅导过程中所存在的最大问题是任何创业成功的案例都 是不能被完全复制和模仿的, 因为, 每一个创业者所面对的创业环境和条件都不可能完全一 致和相同。创业教练是通过有效发问, 就一个关键词, 就学生创业中面临的一个具体目标或 困惑去答疑解惑。一个有效的发问是简明、清晰的焦点集中的具有建设性的问题, 问题的提 出是切重要害能够帮助学生清晰目标, 明确任务的。 


\section{2 理清现状}

无论是企业的管理者还是毫无创业经验的学生创业者, 他们都是从事其创业领域的专家 和权威, 因此, 当他们遇到困难或面对现状时, 容易从自己的主观愿望出发, 对事实的现状 进行分析和评价, 然而, 正所谓 “当事者迷, 旁观者清” 的道理, 往往创业者的分析和判断 过于个人臆断而存在很大的风险和不确定性。这时创业教练可以帮助创业者理清现状, 探寻 创业目标中的关键点、问题点和难点。理清现状也是教练辅导过程中必须要完成的规定动作。 因为任何经验辅导或是商业咨询都不可能一次就全部搞定企业管理者的所有疑惑, 教练技术 也一样忌讳眉毛胡子一把抓。教练技术在创业辅导过程中通过有效对话技术聆听创业者关心 的关键点, 要聚焦一个展开发问, 而创业者尤其是初创阶段的学生创业者他们面对的创业环 境和机会往往是多方面的, 创业教练就是要抓住现状中最大的障碍, 通过 “事实+数据” 的方 法让创业学生能够发现 “优势” 和 “差距” 以及解决问题的关键点。

\section{3 目标分类}

彼得 - 德鲁克说过: “建立目标是一种平衡: 在企业成果与遵循人们所相信的原则之间 的平衡, 在企业当前需要与长远需要之间的平衡, 在期望的结果与可用的资源之间的平衡。” 从创业教练的视角, 我们可以看到一个学生创业项目从初创到成熟过程存在三种表现形式: 愿景目标、表现目标和行动目标。创业教练在创业指导实践中能够将三类不同目标表现形式 进行科学转化。从教练技术的实际应用效果来看, 正是因为创业教练能够帮助学生从宏观的 愿景目标转换成为具体的、明确的、有时间限制的, 以成果为导向的表现目标, 在每个行动 目标的展开落实上又将其转化成为每天去做可以度量的行动目标去加以实现。在三种目标转 换过程中精准表现目标是尤为关键在一环。精准表现目标的核心要素是具体的、可度量的、 可接受的、成果为导向的、有时限的。具备这些条件的表现目标才是创业者当前面临的形势 下最需要解决问题的努力方向。教练技术在帮助创业学生实现目标分类的过程中的实践应用 意义是非常大的。

\section{4. 结语}

在 “大众创业, 万众创新” 的背景下, 大学生创业队伍逐年增加。这就要求我们的创业 指导教师们也要与时俱进, 锐意创新。在面对互联网时代茁壮成长起来当代创业大学生们, 我们必须要完成由传统教师向创业教练的角色转变。在创业教育的方法研究和实践应用中不 断探索新思维和新模式, 教练技术经过多年在企业教练中的实践应用所取得的成功和经验已 经得到了企业及市场的验证和认可, 将教练技术引入到大学生的创业实践指导中是新时期高 校创新创业教育工作实践改革过程的必然选择。

\section{References}

[1] How Entrepreneurship Forgot Capitalism: Entrepreneurship Teaching and Research in Business Schools[J]. R. Daniel Wadhwani. Society. 2012(3).

[2] Exploring the Value Proposition of the Undergraduate Entrepreneurship Major and Elective Based on Student Self-Efficacy and Outcome Expectations[J]. Andrew T. Bernstein,Elias G. Carayannis. Journal of the Knowledge Economy. 2012(3)

[3] The role of entrepreneurship education as a predictor of university students' entrepreneurial intention[J]. Ying Zhang,Geert Duysters,Myriam Cloodt. International Entrepreneurship and Management Journal. 2014(3) 